\title{
L5 Radiculopathy with Neurological Deficit Due To Sacral Insufficiency Fracture
}

ERIC TOUSSIROT, MD, PhD, INSERM CIC-1431, Centre d'Investigation Clinique Biothérapie, and Fédération Hospitalo-Universitaire INCREASE, and Service de Rhumatologie, Centre Hospitalier Universitaire de Besançon, and Département Universitaire de Thérapeutique, Université de Franche Comté, and INSERM U1098, Interactions Hôte-Greffon-Tumeurs, ingénierie cellulaire et génique, Etablissement Français du Sang Bourgogne Franche Comté, Université Bourgogne Franche-Comté; MATTHIEU BEREAU, MD, Service de Neurologie - électrophysiologie clinique, Centre Hospitalier Universitaire de Besançon; SEBASTIEN AUBRY (D), MD, PhD, Service de radiologie, Centre Hospitalier Universitaire de Besançon, and Laboratoire Nanomédecine Imagerie et Thérapeutique EA4662, Université de Franche Comté, Besançon, France. Address correspondence to Prof. E. Toussirot, INSERM CIC-1431, Centre d'Investigation Clinique Biothérapie, Centre Hospitalier Universitaire de Besançon, 25000 Besançon, France. E-mail: etoussirot@chu-besancon.fr. According to current French legislation, observational studies do not require Ethics Committee approval. The patient gave written informed consent to publish the case and imaging material. J Rheumatol 2020;47:939-40; doi:10.3899/jrheum.190517

Sacral insufficiency fractures (SIF) are observed in osteoporotic subjects, with aging, female sex, and corticosteroids as risk factors ${ }^{1,2}$. Teriparatide may be a therapeutic option in such cases, as well as surgical stabilization in recalcitrant cases $^{3}$.

A 67-year-old white woman with steroid-dependent polymyalgia rheumatica developed right buttock pain extending down to the right lateral thigh and leg. On physical examination, tenderness was noted in the right sacral area but there was no motor or sensory impairment. Pelvic computer tomography scan and magnetic resonance imaging (MRI) showed a fracture line along the right sacral ala surrounded by an area of marrow edema and swelling of the right L5 root (Figure 1). SIF associated with L5 radiculopathy was diagnosed and the patient was treated by analgesics, bisphosphonate infusion, and finally, sacroplasty. She had persistent pain 1 month later but repeat MRI did not show cement leakage. Twelve months later, she had persistent pelvic pain radiating in an L5 distribution and motor deficit (right foot dorsiflexion: 3/5). Pelvic MRI showed healing of the fracture with persistent edema of the right L5 root (Figure 2).

Neurologic symptoms associated with SIF are uncommon and occur in $2 \%$ of cases $^{4,5}$. Neurological deficits are exceptional. The mechanisms that may explain neurological involvement include nerve root irritation by the bone edema or the healing process. In general, neurological involvement associated with SIF resolves with the outcome of the fracture $^{3,4}$. In our case, there were neurological sequelae, explained by persistent neurological irritation due to bone callus.

\section{REFERENCES}

1. Lyders EM, Whitlow CT, Baker MD, Morris PP. Imaging and treatment of sacral insufficiency fractures. Am J Neuroradiol 2010;31:201-10.

2. Bydon M, Fredrickson V, De la Garza-Ramos R, Li Y, Lehman RA Jr, Trost GR, et al. Sacral fractures. Neurosurg Focus 2014;37:E12.

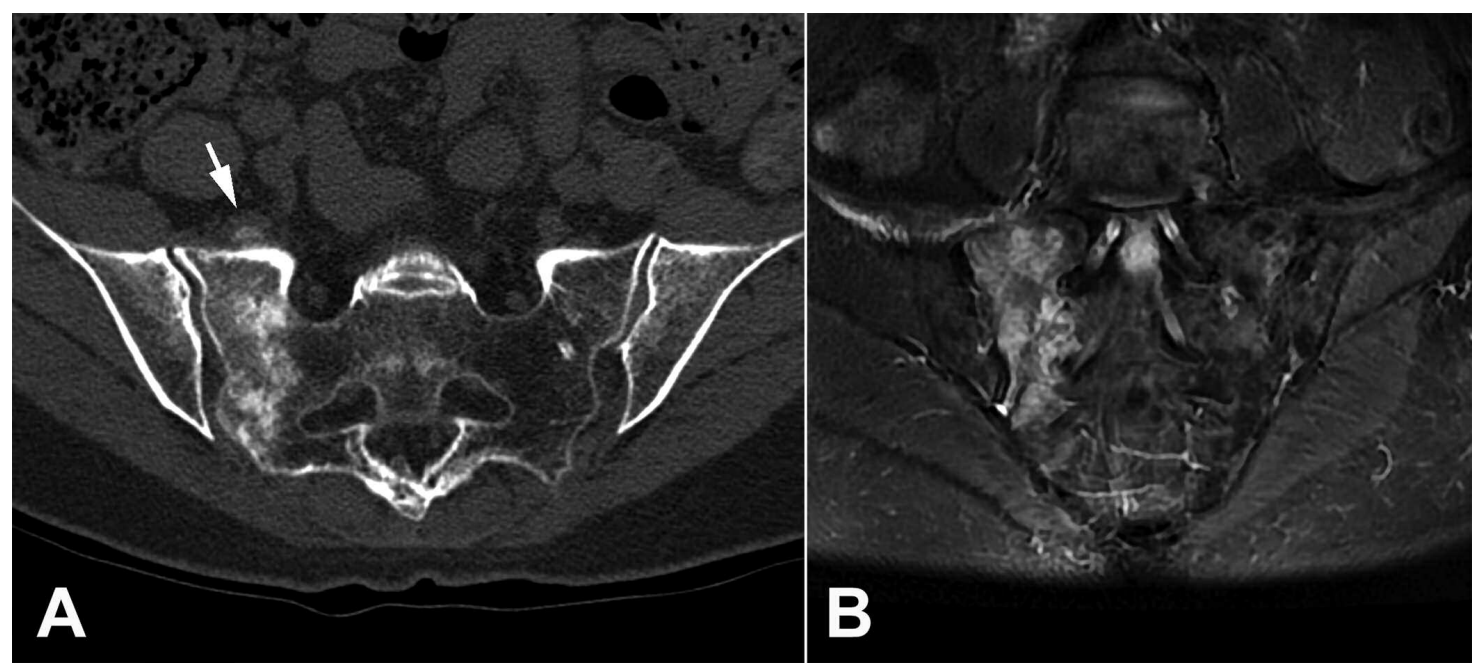

Figure 1. A. Axial CT scan shows a fracture line along with sclerosis of the right sacral ala. Note the fifth lumbar root swelling in contact with bone callus (arrow). B. Coronal STIR MR image reveals bone marrow edema on both sides of the fracture. CT: computed tomography; STIR: short-tau inversion recovery; MR: magnetic resonance.

Personal non-commercial use only. The Journal of Rheumatology Copyright @ 2020 . All rights reserved. 


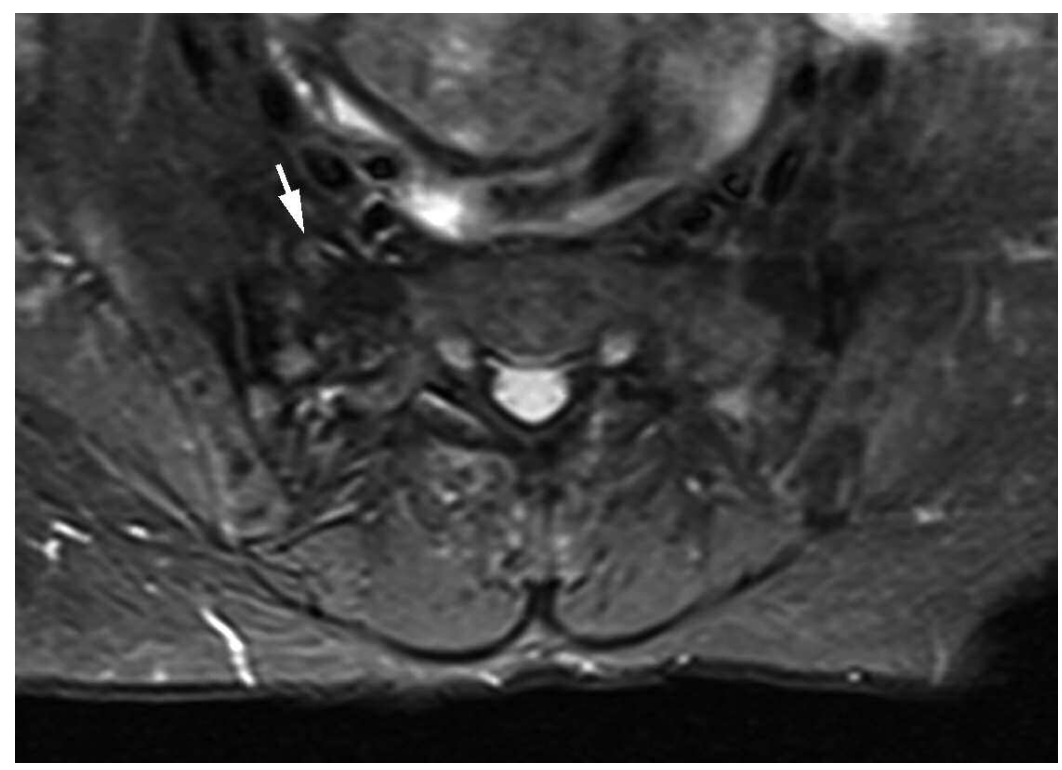

Figure 2. Axial STIR MR image of the sacrum taken 13 months later. While the sacral fracture is healed, edema and swelling of the right L5 root persist (arrow), associated with a linear low-signal image medial to the root consistent with an irritating thorn-shaped callus. STIR: short-tau inversion recovery; MR: magnetic resonance.

3. Su CH, Tu PH, Yang TC, Tseng YY. Comparison of the therapeutic effect of teriparatide with that of combined vertebroplasty with antiresorptive agents for the treatment of new-onset adjacent vertebral compression fracture after percutaneous vertebroplasty. J Spinal Disord Tech 2011;26:200-6.
4. Kondo N, Fujisawa J, Arai K, Kakutani R, Endo N. Sacral stress fracture complicated by $\mathrm{L} 5$ radiculopathy in a patient with rheumatoid arthritis. Acta Med Okayama 2018;72:531-4.

5. Aylwin A, Saifuddin A, Tucker S. L5 radiculopathy due to sacral stress fracture. Skeletal Radiol 2003;32:590-3. 